\title{
Measuring moisture absorption in structural adhesive joints with fibre Bragg grating sensors.
}

\author{
S. Fevery ${ }^{a *}$, H. Hallez ${ }^{\mathrm{b}}$, D. Vandepitte ${ }^{\mathrm{c}}$ and S. Debruyne ${ }^{\mathrm{a}}$ \\ ${ }^{a}$ Department of Mechanical Engineering, KU Leuven University, Bruges, Belgium; \\ ${ }^{b}$ Department of Computer Science, KU Leuven University, Bruges, Belgium; \\ ${ }^{c}$ Department of Mechanical Engineering, KU Leuven University, Heverlee, Belgium; \\ *steven.fevery@kuleuven.be \\ Department of Mechanical Engineering, KU Leuven Bruges Campus \\ Spoorwegstraat 12 - box 7922 \\ 8200 Bruges (Belgium)
}




\title{
Measuring moisture absorption in structural adhesive joints with fibre Bragg grating sensors.
}

\begin{abstract}
The increased joint efficiency, distribution of loads and decrease in stress concentrations have led to the increased use of adhesives for structural bonding. However, there are a limited number of techniques for verifying and monitoring the integrity and durability of adhesive bonds. This paper studies the potential of estimating the curing and ageing of adhesive bulk samples with embedded Fibre Bragg Grating (FBG) sensors through measuring the strain associated with hygroscopic expansion. This is achieved by relating the output of a FBG sensor to the deformation of the structure in which it is embedded. This work considers the possibility of mapping the changing structural resistance to mechanical loading (stiffness) of adhesive bonds as a function of time, under the influence of temperature and moisture as environmental factors. The goal is to map the influence of these environmental factors separately on the one hand, and their combined effect on adhesive bonds, on the other hand.

This study subjects several bulk specimens to various environmental ageing loads. The swelling, associated to moisture absorption and that results in mechanical strain, is measured with FBG sensors. The moisture absorption behavior at different temperatures and environmental relative humidity conditions determined in this way, is verified using classical test methods (e.g. DSC, gravimetric) on multiple fibreless specimens.
\end{abstract}

Keywords: Ageing, Moisture diffusion, Embedded FBG sensors, Gravimetric tests, Structural health monitoring

\section{Introduction}

In the last decade, the increased range of possible structural material combinations such as light metal alloys and reinforced plastics, has pushed the development of new structural adhesive joints in automotive, aerospace and many other industries [1, 2, 3]. Adhesive bonding joins dissimilar materials to obtain structures with a very high strength and excellent fatigue characteristics. It due The continuous bond line and tuned mechanical properties of the adhesive enable optimization of (i) structural stiffness while meeting 
demands on aesthetics, (ii) maintenance flexibility, (iii) sealing and corrosion protection. In addition, adhesive bonding technology is extensively combined with other assembly techniques such as bolting, riveting, spot welding and clinching. Hybrid joining results in fewer stress concentrations, lighter constructions and excellent (dynamic) load transfer characteristics [4].

However, despite the numerous possibilities and advantages mentioned above there is still some scepticism about adhesive bonding technology. One of the main issues here is the complexity of a reliable and adequate estimation of the strength and durability of adhesively bonded structures. The most common and relevant cause of environmental degradation in bonded joints involves the absorption of moisture into the adhesive layer [5]. This effect especially occurs in case of widely applied epoxy-based adhesives. When exposed to a hydrothermal environment, epoxies absorb moisture, greatly affecting the thermomechanical properties and resulting in a significant decrease of the durability and reliability of the structural adhesive joint $[6,7,8]$. Currently, there is no reliable and robust in situ testing methodology that enables adequate monitoring of the bond integrity under static and dynamic loading, thus hindering the potential to facilitate permanent structural health monitoring for structural adhesive joints $[9,10,11]$. Most currently applied techniques for structural health monitoring, quality control and prognosis of adhesive joints are based on ultrasonic methods $[12,13,14,15]$.

This paper is structured as follows. The first part presents and discusses mechanical issues related to environmental effects on (epoxy based) adhesives. A second part extensively discusses the methodology of using FBG sensors and their applicability for structural health monitoring in adhesive joints. The next part deals with sample production while part four discusses the practical tests conducted and the results obtained. The last part concludes on the investigations are discusses further potential and challenges.

\subsection{The influence of moisture on adhesives}

Moisture absorption is one of the most important sources of impairing the mechanical properties of adhesive layers because of introduced physical material changes at a microscopic level [16] which are partly reversible and irreversible. Epoxy adhesives tend 
to absorb ambient moisture which accounts for significant degradation effects like plasticizing $[5,16,17]$, crack growth $[17,18]$, hydrothermal expansion of the adhesive [5, 16] and irreversible deterioration of the adhesive-adherent interface adhesion [19], introduced by e.g. corrosion effects. In addition, the degradation behaviour of adhesive joints is further complicated by the interaction between different environmental factors acting simultaneously. Increased temperature for example, not only speeds up moisture diffusion, it also affects the diffusion mechanism and consequently the type of diffusion law that is valid [20].

\subsection{Sensing moisture diffusion}

Since the use of epoxy resins, moisture detection has been an important issue of research. A straightforward method of determining the rate of moisture diffusion is to weigh a sample of adhesive material before it is immersed in water, and then again periodically until saturation is reached [21]. As described above, moisture is one of the dominant factors in deteriorating mechanical properties like stiffness and strength of actual adhesive bonds. Therefore, a relevant and direct method is to monitor the change of adhesive mechanical stiffness as a function of the absorbed water [22]. There are multiple, well documented methods to analyse the change in mechanical properties of a adhesive materials and bonded joints such as: tensile tests [21], (O)DCB validation tests [23] and single lap joint tests [24]. To define the absolute water content in adhesive bulk material, test methods like the Karl Fischer titration [25] may be applied. I.A. Ashcroft et al. describe a method for monitoring water absorption through depth sensing [26]. Recent developments even involve miniaturized and flexible sensors that monitor moisture diffusion in composites parts in service [27] online. However, the most widely used method to monitor real-time moisture diffusion in adhesives layers are optical fibres (OF) [28]. There are multiple techniques based on OF [29], but most common are (FBG) sensors [28]. 


\subsection{FBG sensing principles}

FBGs are made by exposing the core of a single-mode fibre to a periodic pattern of intense laser light. This exposure produces a permanent periodic modulation with increase of the refractive index in the core of the single-mode optic fibre [30]. This creates a fixed index modulation due to the exposure pattern which is called the Grating [31]. The length of the FBG sensor depends on its application but is normally in the range of 1 to $25 \mathrm{~mm}$. The periodic perturbation in the core refractive index ensures that a small amount of light is reflected [28]. The reflected light signals combine to one large coherent reflection with a particular wavelength as shown in Figure 1.

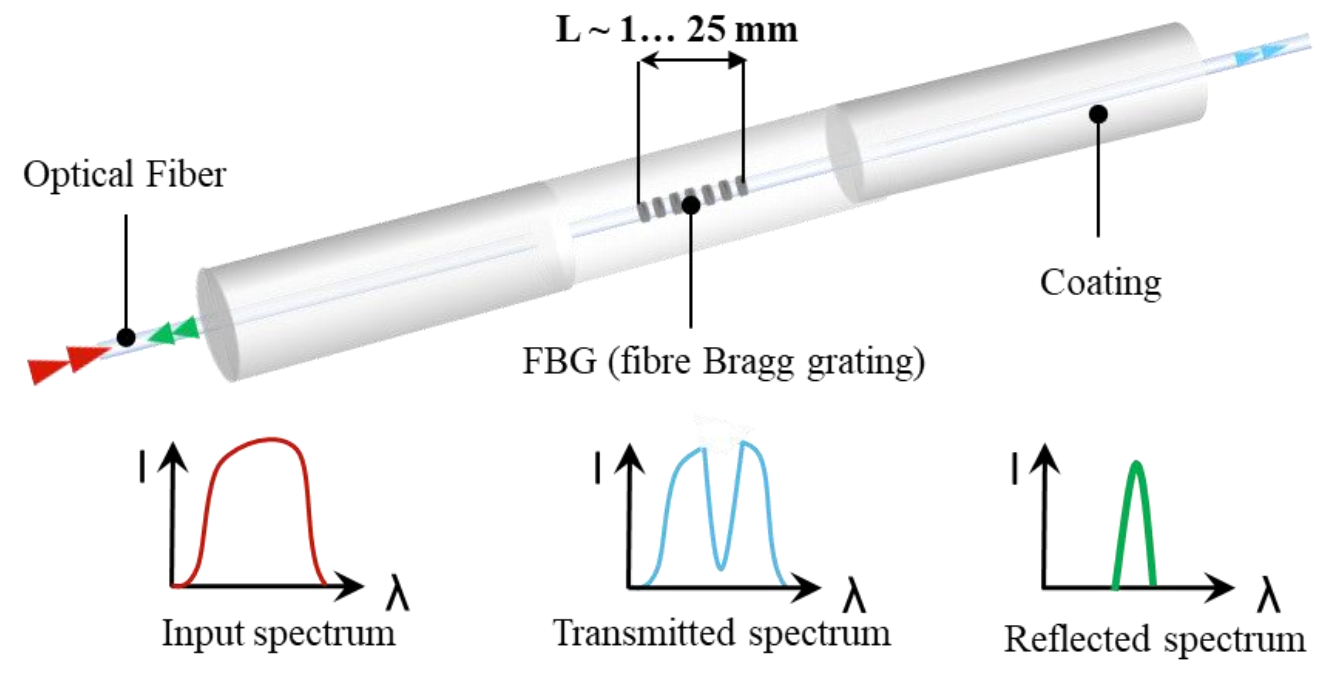

Figure 1: refraction principle of Fibre Bragg Grating sensors

The relevant quantity of the reflected signal is commonly known as the Bragg wavelength $\lambda_{B}$ which is dependent on the effective refractive index of the fibre core $n_{\text {eff }}$ and the period of the grating plane $\Lambda$ and is expressed by equation (1) :

$$
\lambda_{B}=2 n_{e f f} \Lambda
$$

The Bragg wavelength changes due to the applied homogeneous axial strain $\varepsilon$ to the fibre and apparent temperature changes $\Delta T$ from which the relationships are described by:

$$
\frac{\Delta \lambda_{B}}{\lambda_{B}}=\left(1-\rho_{e}\right) \varepsilon+(\alpha+\xi) \Delta T
$$


In this equation $\rho_{e}$ is the elasto-optic coefficient of the fibre optic material (this grating gage factor is measured experimentally), $\alpha$ is the thermal expansion coefficient of the core and $\xi$ the thermo-optic coefficient. The longitudinal strain $\varepsilon$ influence the period of the grating plan $\Lambda$, while the temperature affects both the effective refractive index of the fibre core $n_{e f f}$ and the period of the grating plane $\Lambda[6,32]$.

FBG sensor patterns can be applied (e.g. lasered) on both silica glass and polymer optical fibres [33]. Silica glass fibre based sensors have multiple advantages such as a small size (approximately Ø200 $\mu \mathrm{m}$ including the coating) and low weight which reduce their adverse influence on the mechanical performance of the associated structural joints [28]. The high multiplexing capabilities, immunity to electromagnetic field interference, high corrosion resistance and the redundancy of a dedicated calibration makes them little sensitive to external disturbances [34] and thus quite robust for industrially oriented applications. FBG sensors in general are sensitive for both temperature and strain [35] and changes in these parameters are linearly proportional to changes in the reflected/measured wavelength [34], which also applies to polymer FBG sensors. This latter type of FBG sensors show specific features as a high fracture resistance, low Young's modulus, high flexibility and high temperature sensitivity [36]. Polymer Optical FBG (POFBG) sensors are also found to be very sensitive to moisture in addition to strain and temperature changes, in contrast to silica glass fibre FBG's [37]. This due to the affinity for water of the PMMA carrier, which leads to swelling of the fibre and results in an increase of the refractive index [38]. The disadvantages of polymer FBG is the dramatic loss of the transmitted signal with increasing fibre length so for long distances they have to be connected to silica glass fibres Another disadvantage is the negative thermal-optic coefficient that results in wavelength decrease with temperature increase [36]. Considering the physical fact that moisture absorption strongly relates to the temperature [20] and that sensor sensitivity to humidity and temperature is strongly correlated [33] makes it hard to eliminate temperature change influence from strain measurements performed in an environment with a fluctuating temperature [33]. 
FBG sensors can be applied onto structure surfaces [39] or embedded [40, 41, 42] into the material of a structure during its manufacturing process. It is even possible to embed FBG sensors in adhesive layers during the process of joining two substrates [43].

Nowadays FBG sensors are often used for structural health monitoring on various safetycritical structures: bridges [39, 44], buildings [45], aircraft structures [46], marine vessels [47], offshore platforms and wind turbines [43, 48]. FBG sensors can be used for structural health monitoring of adhesive joints [49], by measuring strain along a bonded region [35]. Micro structured Optical FBG Sensors [50] are applied for in situ shear stress distribution sensing in the context of disbond monitoring of adhesive bonds. Sulejmani et al. [49, 50] present a method that allows determination of the shear stress distribution in an adhesive bond line. Disbonds as small as $100 \mu \mathrm{m}$ can be detected without having to know the exact loading level.

\subsection{Motivation}

In service, adhesive joints are exposed to multiple, combined environmental effects that in most cases adversely affect the stiffness and strength characteristics of the bond. This is usually because of the absorption of environmental moisture by polymeric adhesives, which affects both the mechanical behaviour (plasticizing effect) of the adhesive and the interface between the adherents and the adhesive [5]. As presented before, combined moisture and elevated temperature adversely affects the strength and durability of adhesive joints. Coupled hygro-mechanical finite element analysis (FEA) is a good numerical tool to understand and predict the effect of environmental ageing on the stiffness and strength of bonded joints, taking into account complex bond line geometry. The method mentioned is partly based on the experimental determination of the moisture distribution in the joint as a function of time. This requires a reliable and robust measurement method that can be applied outside lab environments. As mentioned above, silica glass optical fibres are not sensitive to humidity, but only to temperature and strain. This technology thus seems very valuable for the experimental characterization of adhesive swelling due to moisture uptake. The goal of this research is to evaluate the potential of the FBG technology for this purpose. Finite element analysis can be used to determine the degradation of the strength and 
stiffness of the adhesive bond as exposure time proceeds. Appropriate failure criteria are applied to predict the residual strength. In hybrid prognostics, this is matched with realtime monitoring and and used for structural health and life-time prediction [51].

\section{Materials and Methods}

Rectangular epoxy specimens with a length of $300 \mathrm{~mm}$, width of $15 \mathrm{~mm}$ and height of 10 mm (supplementary Figure 10), are each applied with an optical glass fibre of $0.2 \mathrm{~mm}$ (0.125 mm cladding) diameter, centrally located in the specimens. Specimens are prepared from a $2 \mathrm{k}$ epoxy of the type Loctite ${ }^{\circledR}$ EA9450 resin A \& B (volume mixing ratio 50:50). The elastic properties of the epoxy at room temperature are: Young's modulus $\mathrm{E}_{\mathrm{m}}=1.9$ GPa and Poisson's ratio $v_{\mathrm{m}}=0.36$ (obtained by testing of dog-bone epoxy specimen). The corresponding specifications of the embedded glass fibre are, $E_{f}=2 \mathrm{GPa}$ and $\mathrm{v}_{\mathrm{f}}=0.35$ (according to the manufacturer's specification). The optical fibres are equipped with a FBG of $8 \mathrm{~mm}$ with a nominal wavelength $\lambda_{\mathrm{B} 0}=1550 \mathrm{~nm}$ (small deviations are indicated on the sensors specific datasheet). The FBG grating is positioned in the middle of the sample (supplementary Figure 11).

The fibre with Ormocer ${ }^{\circledR}$ coating is positioned in the mould and fixed at one side. After injecting the two-component adhesive mixture into the mould the fibres are tensioned and fixed at the other side as well. Next, each system is being cured for $24 \mathrm{~h}$ at room temperature before being removed from the mould.

All specimens were conditioned at $50^{\circ} \mathrm{C}$ for five days to ensure complete dryness (based on results of Karl Fischer titrations on a regular basis) and thus provide a clear reference situation. Water absorption measurements are carried out using four specimens with a dummy fibre (without active sensor) and one with active fibre immersed in an open tank of demineralized water at $50^{\circ} \mathrm{C}$ and stored in a climate chamber at $95 \% \mathrm{RH}$ (and $50^{\circ} \mathrm{C}$ ) to prevent moisture evaporation. A similar setup was build and kept at room temperature $\left(20^{\circ} \mathrm{C}\right.$ and $\left.50 \pm 5 \% \mathrm{RH}\right)$ and the water tank daily refilled to compensate for evaporation. The test temperatures $\left(20 \& 50^{\circ} \mathrm{C}\right)$ are defined based on the adhesive properties on the data sheet. The general properties are defined at $22^{\circ} \mathrm{C}$. The thermal expansion coefficient of the 
adhesive triples once above $55^{\circ} \mathrm{C}$ and would complicate the comparison of both test temperatures. All specimens were weighed and dimensionally measured to quantify swelling on selected time intervals, using a coordinate measuring machine (CMM, Mitutoyo $^{\circledR}$ BHN 706) with a precision of $4 \mu \mathrm{m} \pm 0.12 \%$ and digital balance (Phoenix instruments ${ }^{\circledR}$ BTG-303) of $1 \mathrm{mg} \pm 0.01 \%$ precision. To determine the relative water increase by mass $M(t)$ per unit of time the following equation is used:

$$
M(t)=\left[\frac{W(t)-W_{0}}{W_{0}}\right] .100
$$

where, $W(t)$ is the weight of the specimen after immersion for time $\mathrm{t}$ (hours) and $W_{0}$ is the initial weight of the dried specimen. In this case, the average weight of the dried specimen is $53.743 \mathrm{~g}$. The relative volume increase $\mathrm{S}(\mathrm{T})$ caused by swelling is determined by:

$$
S(t)=\left[\frac{V(t)-V_{0}}{V_{0}}\right] .100
$$

The active FBG sensors measured strain using an interrogator of type FS $22\left(\mathrm{HBM}^{\circledR}\right)$. Combined with the Catman Easy ${ }^{\circledR}$ DAQ software with optical license enables this to calculate (see further equation 5) the measured strain based on the measured change in reflected wavelength. 


\section{Results and discussion}

1. Monitoring curing of the adhesive specimens

The process of embedding fibre sensors is similar for samples with dummy and active OF. During curing of the adhesive the samples were clamped due to the bolted connections of the mould and active FBG sensors were measuring strain as they were coupled to an interrogator. The FBG sensors were calibrated at $20^{\circ} \mathrm{C}$ and the measurement starts when the adhesive injection into the mould is initiated. The curing of the two-component epoxy is exothermal and hence induces a temperature increase. The observed evolution of recorded strain gives a clear indication of the curing cycle, which is shown in Figure 2.

The presented adhesive mould process can be split in three phases. The first phase concerns the injection of the adhesive into the mould, hence the significant amount of signal scatter observed. The second part shows fluctuations due to various manipulations of the mould during cleaning of the excess adhesive. Region 3 shows the curing process, during which sample A was located in the middle of the mould and was affected by the temperature of the surrounding samples, while sample B was located at the mould border and was able to dissipate its generated heat more freely. During curing of the adhesive the OF initially is

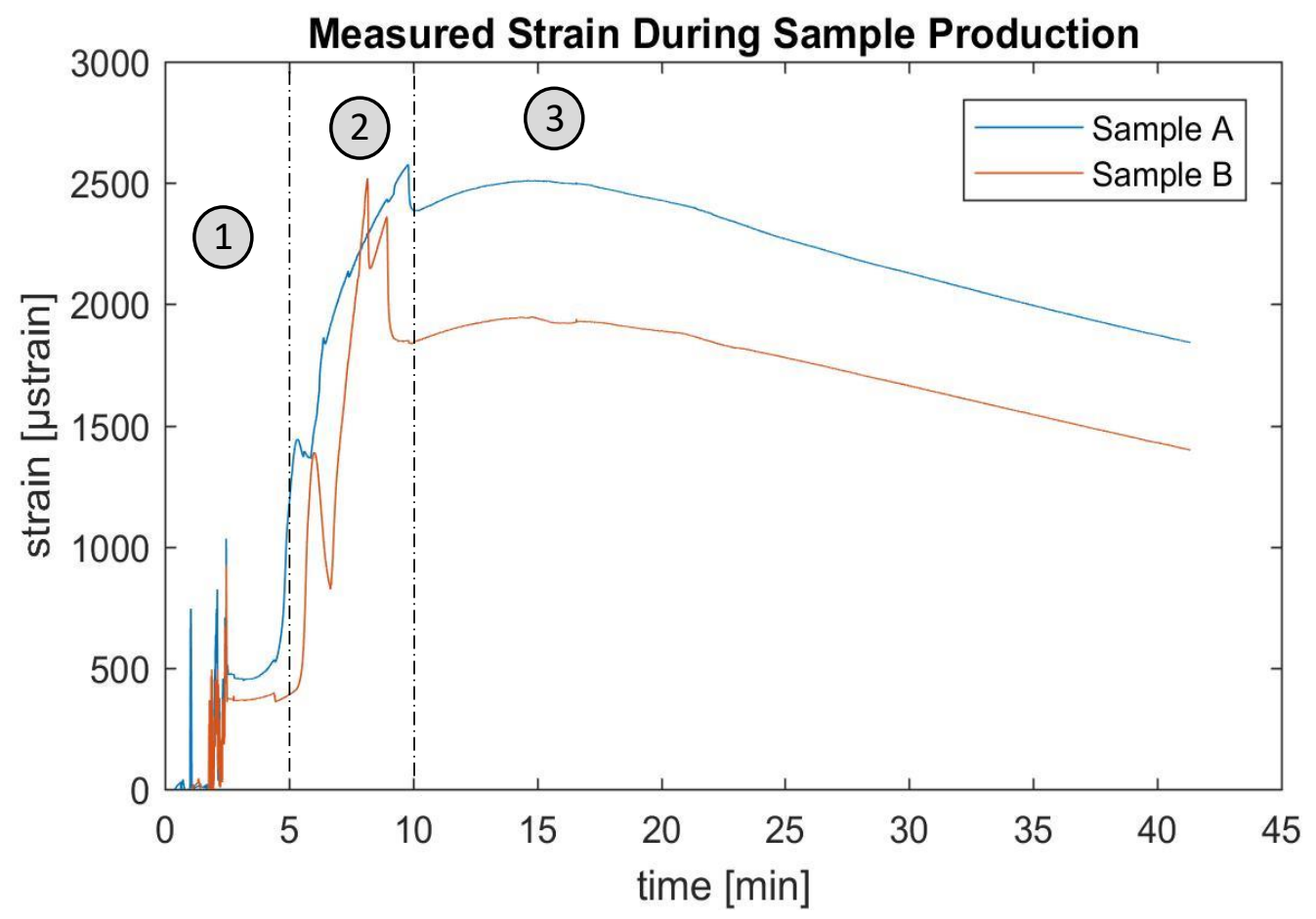

Figure 2: Measured strain during sample production; injection, manipulation and curing 
free to deform. Because of the thermal expansion coefficient $(\alpha)$ of the fibre sensor itself, strain will be detected $\left(0.5 \mu\right.$ strain $/{ }^{\circ} \mathrm{C}$ according to the datasheet). When the viscosity of the adhesive gradually increases during curing the fibre thus accordingly is embedded (bonded) in the adhesive due to the optimal adhesion between the Ormocer ${ }^{\circledR}$ coating of the fibre and the epoxy. The thermal expansion resulting from the exothermic reaction of the two-component adhesive will affect the initial reflected wavelength, however the shape of the response spectra remains unchanged. For that reason, the temperature compensation on the measured values should not be taken into account during further measurements.

\section{Test cycle of the adhesive bulk samples}

As mentioned in previous paragraph, four specimens with a dummy fibre and one with an active FBG are submersed in a container filled with demineralized water at room temperature. The same setup is also stored in a climate chamber at $50^{\circ} \mathrm{C}$ and $95 \% \mathrm{RH}$ to prevent evaporation. The hygroscopic strain at the centre of the specimen, caused by moisture absorption, is recorded by the FBG sensor in the instrumented specimens, of which one in each test environment is analysed. All specimens were dimensionally measured and weighed each 50 hours, using a coordinate measuring machine and digital balance, respectively. The specimens equipped with the active FBG measured permanently during the 250 hours of the ageing process with a sample frequency of one minute. Four samples of every test setup were measured using the CMM with a programmed path that covers over 3600 points on each sample. A Matlab ${ }^{\circledR}$ script was used to calculate the volumes based on the measured points of each sample every 50 hours and results are given in Figure 4. The digital balance applied has a precision of $10 e^{-4} \mathrm{~g}$ which allows to measure behaviours in weight of the analysed material because of the moisture influence. All samples were dried in an environmental chamber at $50^{\circ} \mathrm{C}$ and $0 \% \mathrm{RH}$ for 5 days. Therefore, it is concluded that the amount of moisture in dry state (at time step zero) equals $0 \%$ (practically it should not be higher than 0.15\%). Defined with the Karel Fischer Coulometric titration [25] on $\pm 3 \mathrm{~g}$ material of the samples. Ficks' second law of diffusion is fit to the result samples accordingly (see Figure 3). 

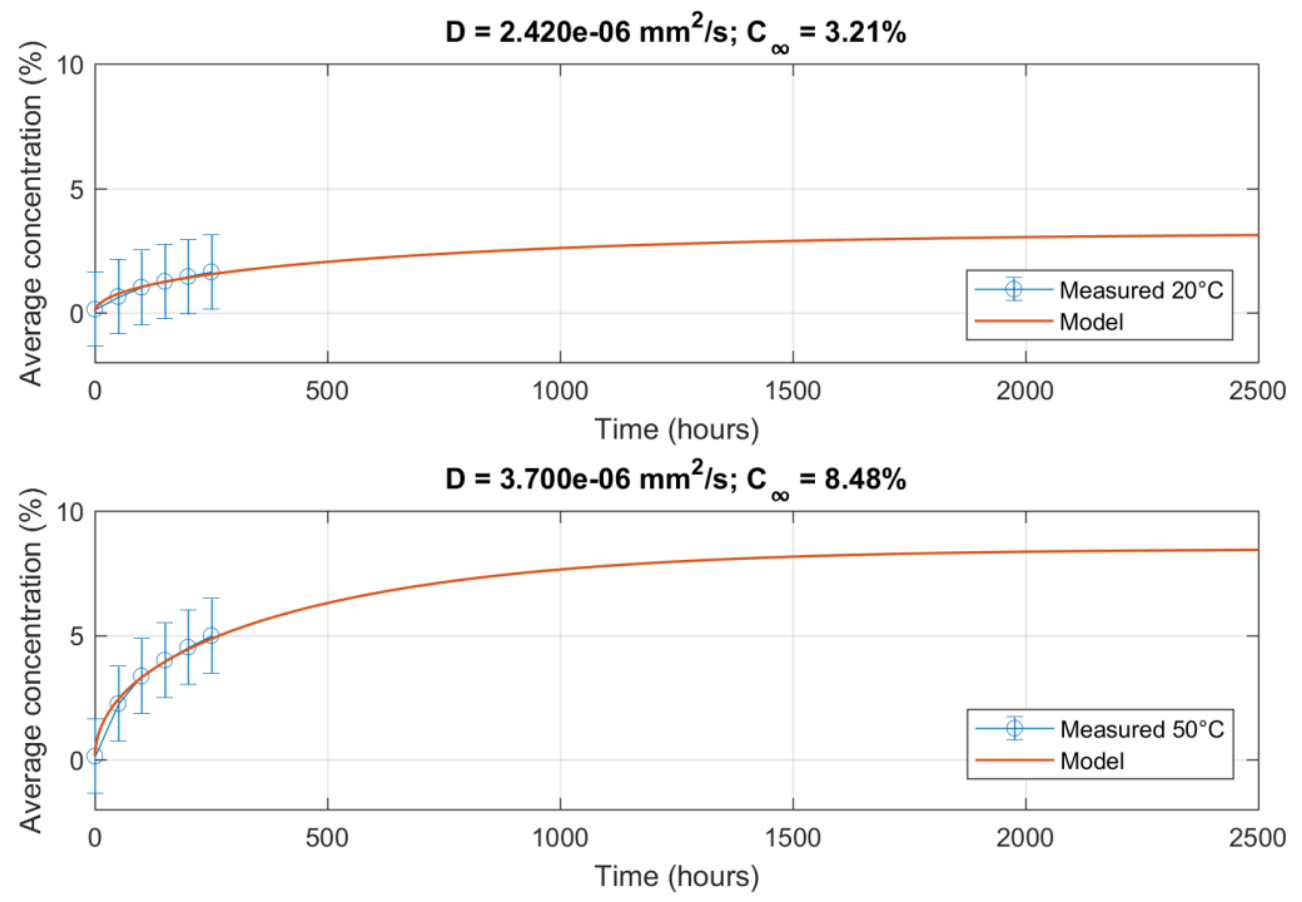

Figure 3: Model based on measured data of moisture uptake

Although no samples are available (yet) until full saturation of the samples is reached, it is however very clear that moisture diffusion shows an exponential curve. The associated coefficient (D) for Fickian diffusion and the maximum (saturation) moisture uptake $\left(\mathrm{C}_{\infty}\right)$ at the specified environments are modelled by a 2D finite element simulation using Matlab $^{\circledR}$ PDE Toolbox. The 2D assumption was made since the dimensions of the specimen allowed the moisture ingress along the longest dimension to be neglected relative to the moisture ingress along shorter dimensions. Using this $2 \mathrm{D}$ finite element simulation an optimization routine was written to minimize the squared sum of the errors between the measurements and the simulations at the measured times. It should be stretched that in this test no saturation was reached for the samples, so further measurements are still required to validate the simulations, to attain a better fit or to evaluate more dedicated models, such as the Langmuir or dual stage model. 

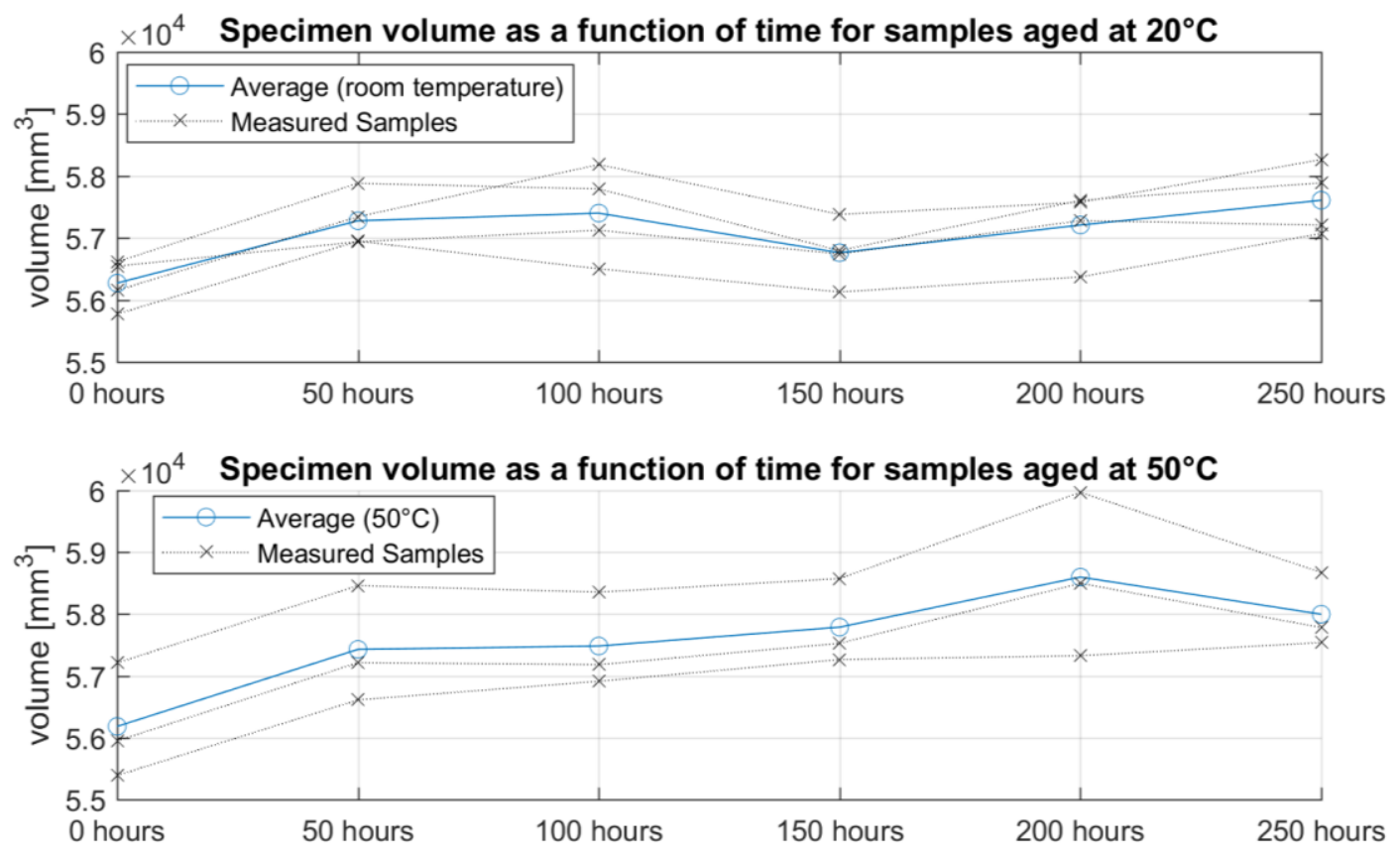

Figure 4: Measured volume as function of time for each test setup

Moisture absorption in epoxy (adhesives) strongly depends on the ambient temperature [52]. The observed changes in volume due to moisture absorption confirm this, as shown in Figure 4. In the first step, regardless of the temperature, the greatest increase can be found. It is interesting that the volume curve for the samples at $20^{\circ} \mathrm{C}$ is characterized by a decrease after 150 hours. This decrease can also be seen after 250 hours in the samples that are aged at $50^{\circ} \mathrm{C}$. To validate the measured volumes, the weight (Figure 5) and length (Figure 6) of the samples is considered as well. From this data it can be deduced that the progression of moisture uptake (and thus sample mass) is steadily rising. Because the CMM's measuring points are programmed, there is a limited number of measured points. As a result the true sample volume is only determined approximately. Therefore, immersing the samples in a bath, at the same temperature as the test environment could yield better results. 

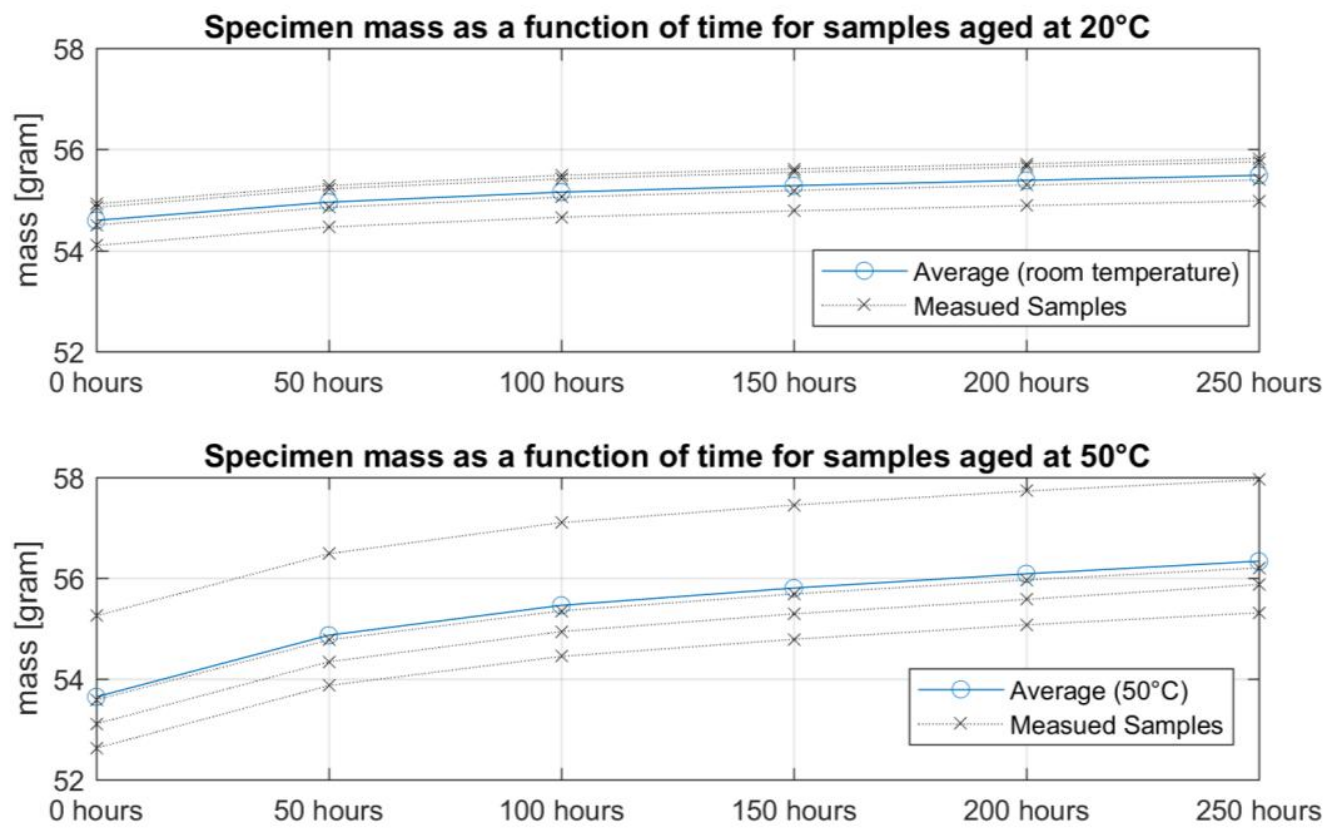

Figure 5: Measured mass as function of time for each test setup
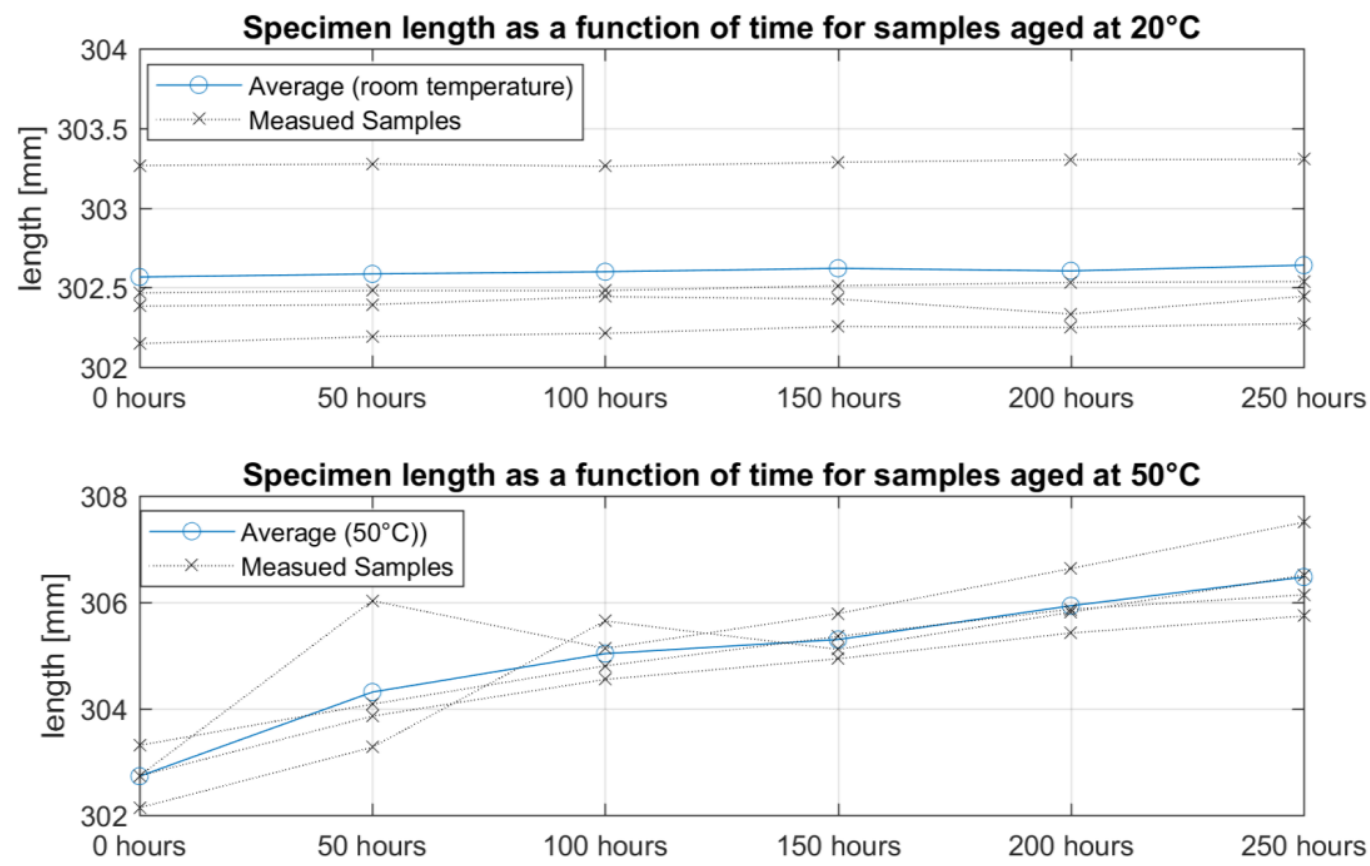

Figure 6: Measured length as function of time for each test setup 


\subsection{Temperature influence on FBG sensors}

Since the FBG sensors are sensitive to temperature variations while mechanical strain changes are being applied, the amount of strain, attributed to temperature changes solely, has to be determined. The samples used for ageing testing were calibrated at room temperature $\left(20^{\circ} \mathrm{C}\right)$. Therefore, an additional test was performed on a dry sample which was calibrated at $20^{\circ} \mathrm{C}$ and stored in a climate chamber at $50^{\circ} \mathrm{C}$ and $0 \% \mathrm{RH}$ for 2000 minutes. Because in this case only temperature changes occur, the measured strain change is considered to be solely related to changing temperature. As a result, the measured curve (Figure 7) can be used for temperature compensation of moisture absorption measurements conducted at $50^{\circ} \mathrm{C}$.

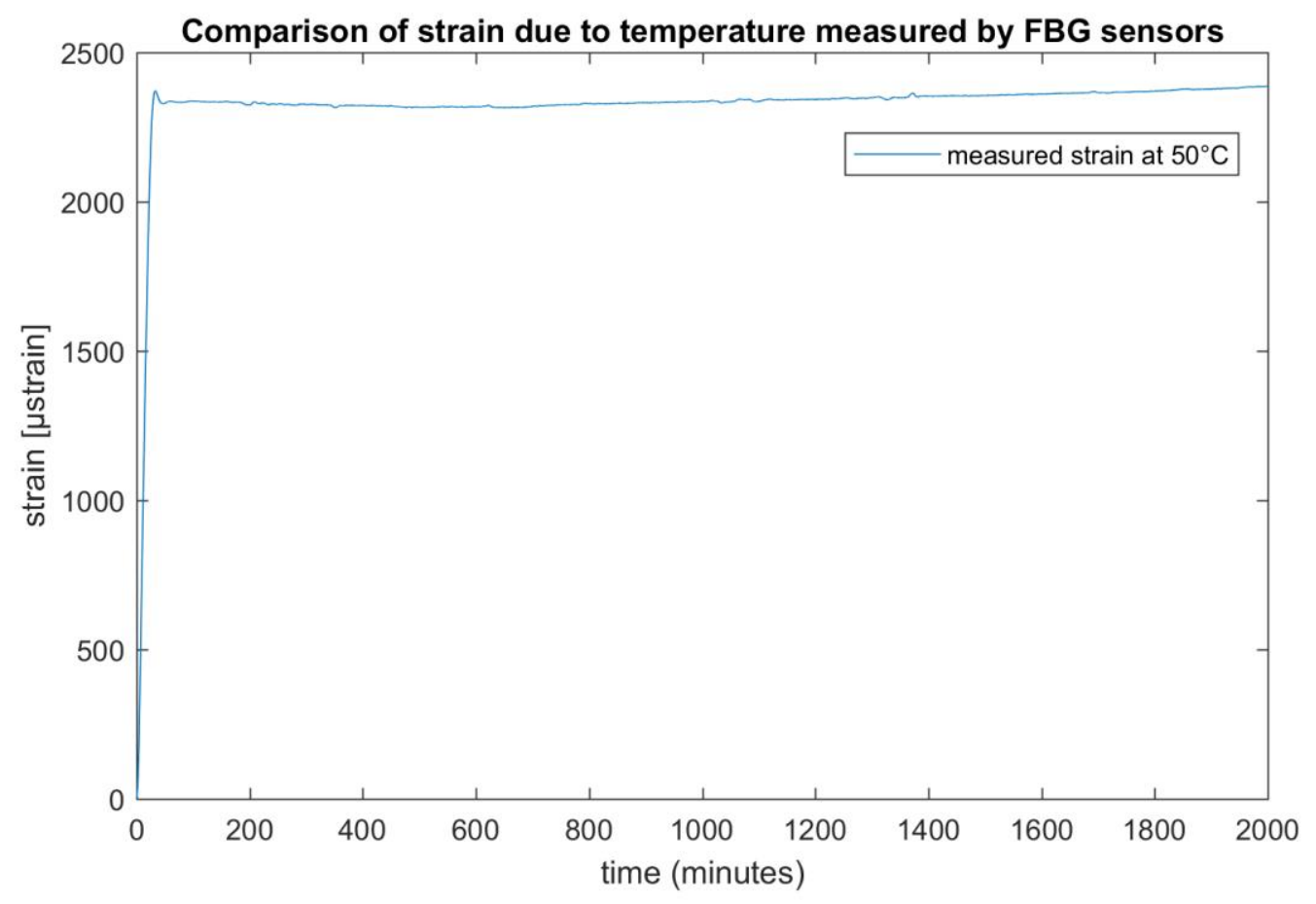

Figure 7: Comparison of strain due to temperature at $50^{\circ} \mathrm{C}$ measured by FBG sensors

The curve shown in figure 7 starts at $20^{\circ} \mathrm{C}$ and quickly rises to $50^{\circ} \mathrm{C}$, being the preprogrammed climate chamber temperature. Although this temperature should be constant, the recorded curve shows a slightly different trend. The observed steady temperature increase of less than $0.5 \%$ of the nominal temperature $\left(50^{\circ} \mathrm{C}\right)$ in a time frame 
of 1200 minutes (or 20 hours) corresponds to temperature accuracy specifications of the climate chamber. It must be noted that the latter is installed in a closed room.

\subsection{CMM versus FBG}

This research applies FBG sensors embedded in adhesive bulk samples for measurement of strain $\varepsilon$ due to moisture absorption. For every case the measured FBG strain values were compared with the change in length (x-axis) of the samples measured with the CMM. The total strain $\varepsilon_{t}$ values determined with the FBG are calculated based on the changes in the reflected Bragg wavelength using equation 5.

$$
\varepsilon_{t}(t)=\frac{\lambda_{r}-\lambda_{b}}{\kappa * \lambda_{b}}
$$

Where $\lambda_{b}$ means base Bragg wavelength, $\lambda_{r}$ the reflected Bragg wavelength and $\kappa$ the gage factor which is fibre specific. According to the manufactures' specifications is it equal to 0.78 in this case. Due to the fact that FBG sensors also serve as temperature sensors and both active FBG sensors were calibrated at $20^{\circ} \mathrm{C}$, a temperature compensation is applied, as indicated in Figure 7. The actual total measured strain $\varepsilon_{t}$ includes both temperature and moisture influences and is calculated using eq. (5). The thermally introduced strain was determined experimentally (Figure 7), so the strain behavior related solely to moisture uptake $\varepsilon_{m}$ - is presented in Figure 8. 

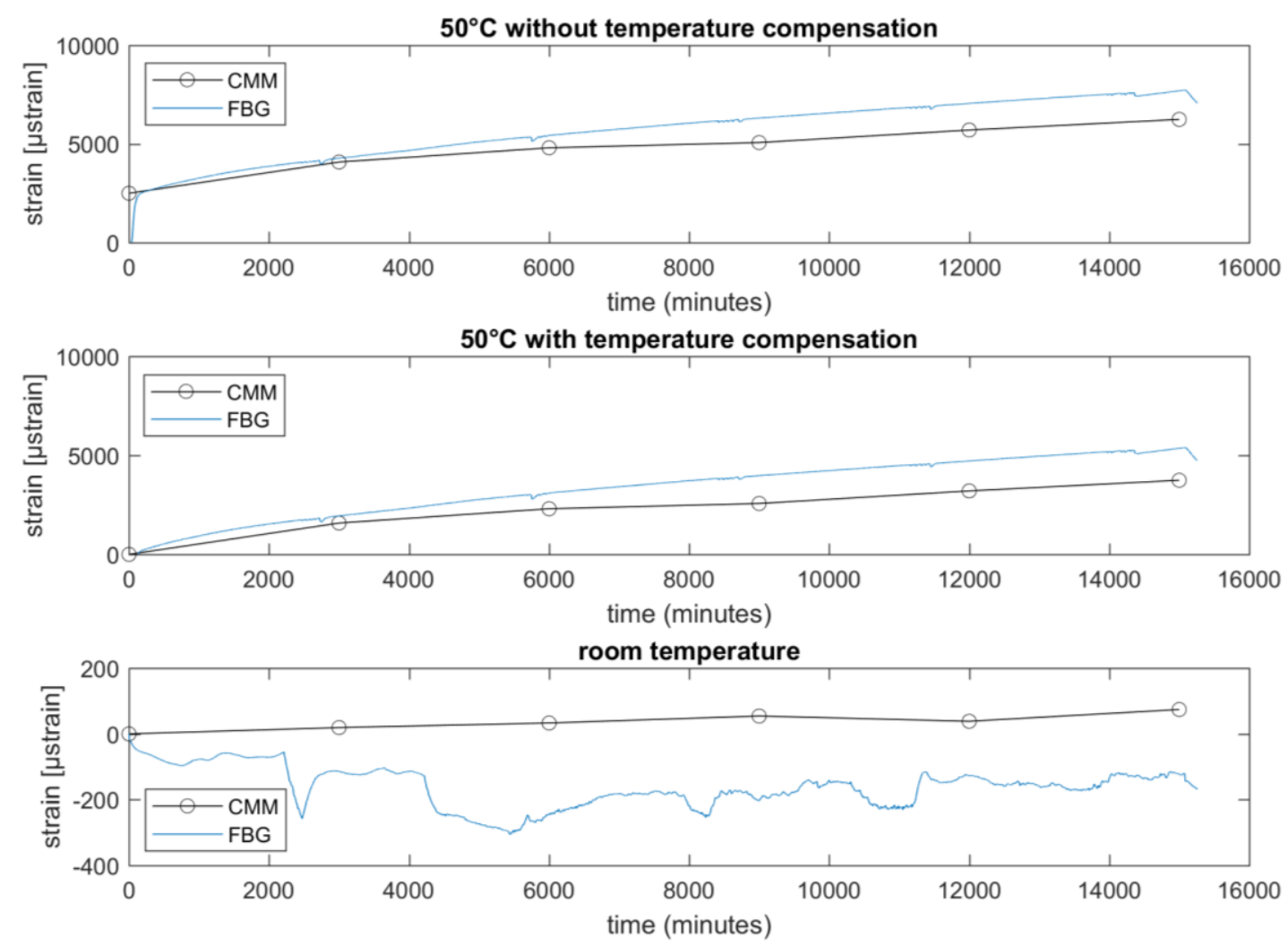

Figure 8: Strain measured with CMM versus FBG

Strain values obtained by applying the FBG sensors are higher than the associated measured sample deformation with the CMM. This results from the fact that the measuring cycles with the CMM took one hour for each sample and that these measurements were performed at room temperature. The samples that were aged at $50^{\circ} \mathrm{C}$ can cool down for one hour and then have to reheat to $50^{\circ} \mathrm{C}$. This causes a delay in the saturation process which does not affect the sample that contains the active FBG sensor. Based on the results of the Karel Fischer test (Table 1), there can be shown that the sample with the active FBG has effectively absorbed more moisture.

Table 1: Moisture percentage defined with Karel Fischer Coulometric titration.

Sample specifications Absolute mass (\%) of moisture

Dried (before ageing) $0.145 \%$

Aged for $250 \mathrm{~h}$ at room temperature $2.222 \%$

Aged for $250 \mathrm{~h}$ at $50^{\circ} \mathrm{C} \quad 3.400 \%$

Aged for $250 \mathrm{~h}$ at $50^{\circ} \mathrm{C}$ (active $\mathrm{FBG}$ ) $\quad 5.810 \%$ 
During exposure of an adhesive bulk sample to moisture and changing room temperatures, the FBG strain values can oscillate. Due to the fact that FBG sensors are more sensitive to temperature variations than strain derived from swelling of the sample by moisture uptake, the values measured with the FBG sensors at room temperature (walk-in environmental testing lab) are somewhat overruled by the strain related to the temperature fluctuations in the lab. It is therefore recommended to use an additional sensor to compensate for the influence of temperature in test environments with varying temperatures.

\subsection{Results of the FBG measurements}

Moisture causes swelling of the adhesive in all directions. The embedded FBG sensors only measure strain in the longitudinal direction of a specimen. Before comparing the measured strain, captured by the FBG sensors, with the specimen length change measured with the CMM, knowledge of the FBG's orientation within the specimen is crucial. To define the orientation of the FBG sensor in the adhesive bulk sample, an X-ray $\mu \mathrm{CT}$ computed tomography scan (Phoenix Nanotom CT scanner) on one of the tested samples was executed. A scan of the region of interest of the sample is presented in Figure 9. By slicing through the 3D-scan the position and orientation of the fibre can be mapped. From these observations, it can be concluded that the fibre alignment nicely coincides with the longitudinal direction of the specimen and thus also matches the intended measurement direction. 


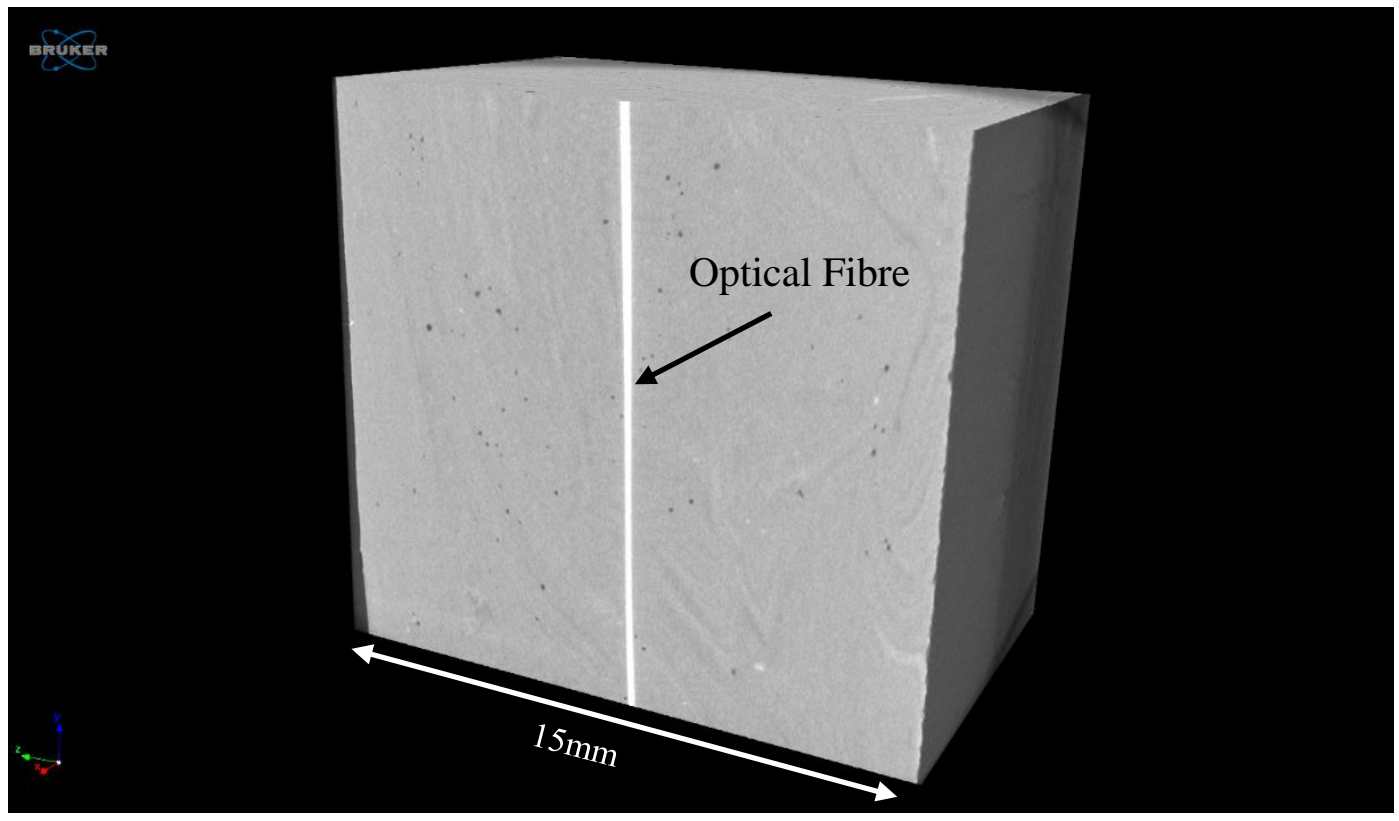

Figure 9: a X-ray $\mu \mathrm{CT}$ computed tomography scan of the sample containing a FBG sensors

3. Changes of glass transition temperature $\mathrm{T}_{\mathrm{g}}$

The initial glass transition temperature $\mathrm{T}_{\mathrm{g}}$ of the epoxy used is $50^{\circ} \mathrm{C}$ according to the manufacturer's datasheet. Moisture absorption leads to a reduction of the $\mathrm{T}_{\mathrm{g}}$ [17], even specimens that are "dried" after saturation will not fully recover their original $\mathrm{T}_{\mathrm{g}}$ value [53]. This may indicate that the aging at $50^{\circ} \mathrm{C}$ is above the $\mathrm{T}_{\mathrm{g}}$ and results in a decrease of the fracture toughness and hence may reduce the elastic modulus and strength of resin/adhesive [17]. $1 \%$ of mass gain during ageing due to moisture absorption, results for all epoxy and hardener combinations tested in a decrease of $\mathrm{T}_{\mathrm{g}}$ by about $10^{\circ} \mathrm{C}$ [54]. To investigate the transformation of the $\mathrm{T}_{\mathrm{g}}$ according to the moisture absorption, a Differential Scanning Calorimetry (DSC) was carried out on a dry and aged specimen and compared with the results of Table 1 . The test equilibration was conducted at $-60^{\circ} \mathrm{C}$ isothermal for a time frame of 2 minutes. The ramp is defined as $10^{\circ} \mathrm{C} / \mathrm{min}$ to $120^{\circ} \mathrm{C}$ followed by the same speed to $-60^{\circ} \mathrm{C}$ and back to $120^{\circ} \mathrm{C}$ for both aged and dry samples. Due to the size of the samples and not reaching saturation during the aging cycles, the with DSC investigated parts (between 6 and 10mg each) of the samples derive from the outer layer. Samples are tested every day of the 5 days at $50^{\circ} \mathrm{C}$ and $0 \% \mathrm{RH}$ (dry cycle) to define the moment of $\mathrm{C}_{0}$ and at the end of the ageing cycles. The determined $\mathrm{T}_{\mathrm{g}}$ of the samples aged at $20^{\circ} \mathrm{C}$ is reduced from $50^{\circ} \mathrm{C}$ to $42.05^{\circ} \mathrm{C}$ and to $29.82^{\circ} \mathrm{C}$ for the samples aged at $50^{\circ} \mathrm{C}$. 


\section{Conclusion}

Moisture contamination leads to diffusion and changes the mass and volumetric parameters of epoxy adhesives which induces strain in the adhesive layer. In this paper the use and potential of FBG sensors is successfully demonstrated as a reliable in-situ measure device for measuring the strain due to moisture absorption in adhesive bulk samples. However, this research does not focus on a dedicated analysis of the exact physical mechanisms behind moisture absorption in epoxy materials or adhesives. This was out of the scope and would be the subject of other or further research.

It has also been shown that the effect of temperature on moisture absorption is significant and the work outlines how this effect can be dealt with.

The influence of the FBG sensor in the adhesive bulk samples must be further investigated, and in adhesive joints with smaller adhesive thicknesses as well. However, it must be taken into account that the temperature should be separately monitored in order to determine the measured strain due to moisture absorption with sufficient accuracy. 


\section{References}

[1] T. Banres and I. Pashby, "Joining techniques for aluminium spaceframe used in automobiless Part II - adheisve bonidng and mechanical fasteners," Journal of Material Processing Technology, vol. 99, pp. 72-79, 2000.

[2] M. Davis and D. Bond, "Principles and practices of of adhesive bonded structural joints and repairs," International Journal of Adhesion \& Adhesives , vol. 19, pp. 91$105,1999$.

[3] M. Banea and L. da Silva, "Adhesivley bonded joints in composite materials: an overview," Journal of Materials: Design and Applications, vol. 223, pp. 1-18, 2009.

[4] L. da Silva, A. Öschner and A. Pirondi, Eds., Hybrid adheisve joints, Berlin: Springer, 2011.

[5] I. Ashcroft and J. Comyn, "Effect of Water and Mechanical Stress on Durability," in Handbook of Adhesion Technology, vol.2, L. da Silva, A. Öschner and R. Adams, Eds., Berlin, Springer, 2011, pp. 789-822.

[6] D. Karakelas, J. Cugnoni and J. Botsis, "Monitoring of hygrothermal ageing effects in an epoxy resin using FBG sensor: A methodoligical study," Composite Science and Technology, vol. 69, pp. 507-514, 2009.

[7] L. El sa'ad, M. I. Darby and B. Yates, "Moisture absortpion by epoxy resins: the reverse thermal effect," Journal of Material Science, vol. 25, pp. 3577-3582, 1990.

[8] T. Glaskova-Kuzmina, A. Aniskevisch, J. Sevcenko, A. Borriello and M. Zarrelli, "Cyclic Moisture sorption and its Effects on the Thermomechanical Properties of Epoxy and Epoxy/MWCNT Nanocomposite," Polymers, vol. 11, pp. 1383-1397, 2019.

[9] H. Pfieffer, F. Fransens and M. Wevers, "Durability and Self-Testin of Sensor bondings used in Structural Health Monitoring," in EU Project Meeting on Aircraft Integrated Structural Health Assessment (AISHA), Leuven, 2007.

[10] B. Ehrhart, B. Valeske, M. C and C. Bockenheimer, "Methods for the quality assessemnt of Adhesive Bonded CFRP Structures- A Resumé," in 2nd International Symposium on NDT in Aerospace, Hamburg, 2010.

[11] M. Abdel Wahab, Fatigue in adhesivley Bonded Joints: A review, vol. /, Ghent: ISRN Materials Science, 2012, p. 25.

[12] G. Shui, Y. Wang, P. Huang and J. Qu, "Nonlinear ultrasonic evaluation of the fatigue damage of adhesive joints," NDT \& E International, vol. 70, pp. 9-15, 2015.

[13] W. Roth and V. Giurgiutiu, "Structural helath monitoring of an adhesive disbond through electromechanical impedance spectrocopy," International Journal of Adhesion and Adhesives, vol. 73, pp. 109-117, 2017.

[14] R. Adams, "Nondestructuve Testing," in Handbook of adhesion technology, L. da Silva, A. Oechsner and R. Adams, Eds., Springer, Cham, 2017.

[15] R. Adams and B. Drinkwater, "Nondestructive testing of adhesively-bonded joints," NDT\&E international, vol. 2, pp. 93-98, 1997. 
[16] M. Wahab, A. Crocombe, A. Beevers and K. Ebtehaj, "Coupled stress-diffusion analysis for durability study in adhesively bonded joints," International Journal of Adhesion \& Adhesives, vol. 22, pp. 61-73, 2002.

[17] S. Budhe, M. Banea, S. de Barros and L. da Silva, "An update review of adhesively bonded joints in composite materials," International Journal of Adhesion and Adhesives, vol. 72, pp. 30-42, 2017.

[18] A. Higgens, "Adhesive bonding of aircraft structures," International Journal of Adhesion \& Adhesives, vol. 20, pp. 367-376, 2000.

[19] S. Sugiman, A. Crocombe and I. Aschroft, "experimental and numerical investigation of the static responseof environmentally aged adhesively bonded joints," International Journal of Adhesion \& Adhesives, vol. 40, pp. 224-237, 2013.

[20] N. Datla, J. Ulicny, B. Carlson, M. Papini and J. Spelt, "Mixed-mode fatigue behavior of degraded toughened epoxy adhesive joints," International Journal of Adhesion \& Adhesives, vol. 31, pp. 88-96, 2011.

[21] A. Ilioni, P. Le Gac, C. Badulescu, D. Thévenet and P. Davies, "Prediction of Mehanical Behaviour of a Bulk Epoxy Adhesive in a Marine Environment," The Journal of Adhesion, vol. 95, pp. 64-84, 2019.

[22] I. Aschcroft and G. Spinks, "A method of monitoring water absorption in polymers using a depth sensing indentation system," Journal of Materials Research, vol. 11, pp. 529-536, 1996.

[23] P. Fernandes, G. Viana, R. Carbas, J.C., M. Costa, L. da Silva and M. Banea, "The influence of water on the fracture envelope of an adhesive joint," Theoretical and Applied Fracture Mechanics, vol. 89, pp. 1-15, 2017.

[24] S. Sugiman, A. Crocombe and I. Aschroft, "Experimental and numerical investigation of the static response of environmental aged adhesively bonded joints," International Journal of Adhesion \& Adhesives, vol. 40, pp. 224-237, 2013.

[25] E. Scholz, Karl Fischer Titration: Determination of Water, Berlin Heidelberg: Springer-verlag, 1984.

[26] I. Ashcroft and G. Spinks, "A method of monitoring water absorption in polymers using a depth sensing indentation system," Journals of Materials Research, vol. 11, 1995.

[27] M. Hübner, D. Lepke, E. Hardi, M. Koerdt, A. Herrmann and W. Lang, "Online Monitoring of Moisture Diffusion in Carbon Fiber Composites Using Miniaturized Flexible Material Integrated Sensors," Sensors, vol. 19.8, no. 1748, 2019.

[28] M. Mieloszyk and W. Ostachowicz, "Moisture contamination detection in adhesive bond usig embedded FBG sensors," Mechanical Systems and Signal Processing, vol. 84, pp. 1-14, 2017.

[29] C. Bellot, M. Olivero, M. Sangermano and M. Salvo, "Towards self-diagnosis composites: Detection of moisture difusion through epoxy by embedded evanescent wave optical fibre sensors," Polymer Testing, vol. 71, pp. 248-254, 2018.

[30] Y.-J. Rao, "Review Article: In-fibre Bragg grating sensors," Measurment Science and Technology, vol. 8, pp. 355-375, 1997.

[31] FBGS, "FBG principle," FBGS, [Online]. Available: https://fbgs.com/technology/fbg-principle/. [Accessed 0409 2019]. 
[32] E. Udd, "Fiber grating sensors," in Fiber Optic sensors: An introduction for Engineers and Scientists 2nd Edition, E. Udd and B. Spillman Jr., Eds., Hoboken, New Jersey, John Wiley \& Sons, Inc, 2011, pp. 399-450.

[33] D. Webb, "Fibre Bragg grating sensors in polymer optical fibres," Measurement Science and Technology, vol. 26, 2015.

[34] E. Udd, "The emergence of fiber optic sensor technology," in Fiber optic sensors: An introduction for engineers and Scientists 2 nd edition, E. Udd and W. Spillman JR, Eds., Hoboken, New Jersey, John Wiley \& Sons, inc, 2011, pp. 13-20.

[35] L. Canal, R. V. G. Sarfaraz, J. Botsis, M. V. and H. Limberger, "Monitoring strain gradients in adhesive composite joints by embedded fiber Bragg grating sensors," Composite structures, vol. 112, pp. 241-247, 2014.

[36] G. Rajan, M. S. Y. Ramakrishnan, E. Ambikairajah, G. Farrel and G. Peng, "Experimantel Study and Analysis of a Polymer Fiber Bragg Grating Embedded in a Composite Material," Journal of Lightwave Technology, vol. 32, 2014.

[37] W. Zhang, D. Webb and G. Peng, "Investigation Into Time Response of Polymer Fiber Bragg Grating Based Humidity Sensors," Journal of Lightwave technology, vol. 30, pp. 1090-1096, 2012.

[38] N. Harbach, Fiber Bragg Grating in Polymer optical Fibers, Lausanne: école Polytechnique fédérale de lausanne, 2008.

[39] T. Chan, L. Yu, H. Tam, Y. L. S. NI, C. W.H. and L. Cheng, "Fiber Bragg grating sensors for structural health monitoring of Tsing Ma bridge: Background and experimental observation," Engineering structures, vol. 28, pp. 648-659, 2006.

[40] P. Biswas, S. Bandyopadhyay, K. Kesavan, S. Parivallal, B. Arun Sundaram, K. Ravisankar and K. Dasgupta, "Investigation on packages of fiber Bragg grating for use as embeddable strain sensor in concrete structure," Sensors and Actuators A: Physical, vol. 157, pp. 77-83, 2010.

[41] K. Kuang, R. Kenny, M. Whelan, W. Cantwell and P. Chalker, "Embedded fibre Bragg grating sensros in advanced composite materials," Composites Science and Technology, vol. 61, pp. 1379-1387, 2001.

[42] R. Ramly, W. Kuntjoro and M. Rahman, "Using Embedded Fiber Bragg Grating (FBG) Sensors in Smart Aircraft Structure Materials," Procedia Engineering, vol. 41, no. International symposium on Robotics ans Intelligent Sensors 2012, pp. 600606, 2012.

[43] S. Kim, W. Kang, M. Jeong, I. Lee and I. Kwon, "Deflection Estimation of a Wind Turbine Blade Using FBG Sensors Embedded in the Blade Bonding Line," Smart materials and structures, vol. 22, 2013.

[44] B. Costa and J. Figueiras, "Evaluation of strain monitoring systems for axisting steel railway bridges," Journal of Constructional steel research, vol. 72, pp. 179191, 2012.

[45] H.-N. Li, D.-S. Li, L. Ren, T.-H. Yi, Z.-G. Jia and K.-P. Li, "Structural health monitoring of innovative civil engineeering structures in Mainland china," Structural monitoring and Maintenance, vol. 3, pp. 1-32, 2016. 
[46] Z. Ma and X. Chen, "Giber Bragg Gratings Sensors for Aircraft Wing Shape Measurement: Recent Applications and Technical Analysis," Sensors, vol. 19, no. 55, pp. 1-25, 2018.

[47] J. Kiddy, C. Baldwin and T. Salter, "Hydrostatic testing of a manned underwater vahicle using Fiber Optic Sensors," in Proceedings of the Oceans conference MTS/IEEE, Washington, 2005.

[48] L. Sun, H. Li, L. Ren and Q. Jin, "Dynamic response meausrement of offshore platform model by FBG sensors," Sensors and Actuators A, vol. 136, pp. 572-579, 2007.

[49] S. Sulejmani, C. Sonneveld, T. Geernaert, G. Luyckx, P. Mergo, W. Urbanczyk, K. Chan, H. Thienpont and F. Berghmans, "Disbond monitoring in adhesive joints using shear stress optical fiber sensors," Smart material structures, vol. 23, 2014.

[50] S. Sulejmani, C. Sonnenfeld, T. Geernaert, G. Luyckx, P. Mergo and e. al.., "Adhesive Disbond Monitoring with Microstructured optical Fiber Bragg Grating Sensors," in 7th European Workshop on Structural Health Monitoring, Nantes, 2014.

[51] I. A. Ashcroft, M. Abdel Wahab and A. Crocombe, "Prediciting Degradation in Bonded Composite Joints Using a Semi-Coupled Finit-Element Method," Mechanics of Advanced Materials and Structures, vol. 10, pp. 227-248, 2003.

[52] Z. Ahmad, M. Ansell and D. Smedley, "Moisture Absorption Characteristics of Epoxy Based Adhesive Reinforced with CTBN and Ceramic Particles for Bondedin Timber Connection: Fickian or Non-Fickian Behaviour," Materials Science and Engineering, vol. 17, no. Conference series, 2011.

[53] Y. Zhang, R. Adams and L. da Silva, "Absorption and glass transition temperature of adhesive exposed to water and toluene," International Journal of Adhesion \& Adhesives, vol. 50, pp. 85-92, 2014.

[54] M. Lai, J. Botsis, J. Cugnoni and D. Coric, "An experimental-numerical study of moisture absorption in an epoxy," Compistes: Part A, vol. 43, pp. 1053-1060, 2012. 


\section{Supplementary Figures}

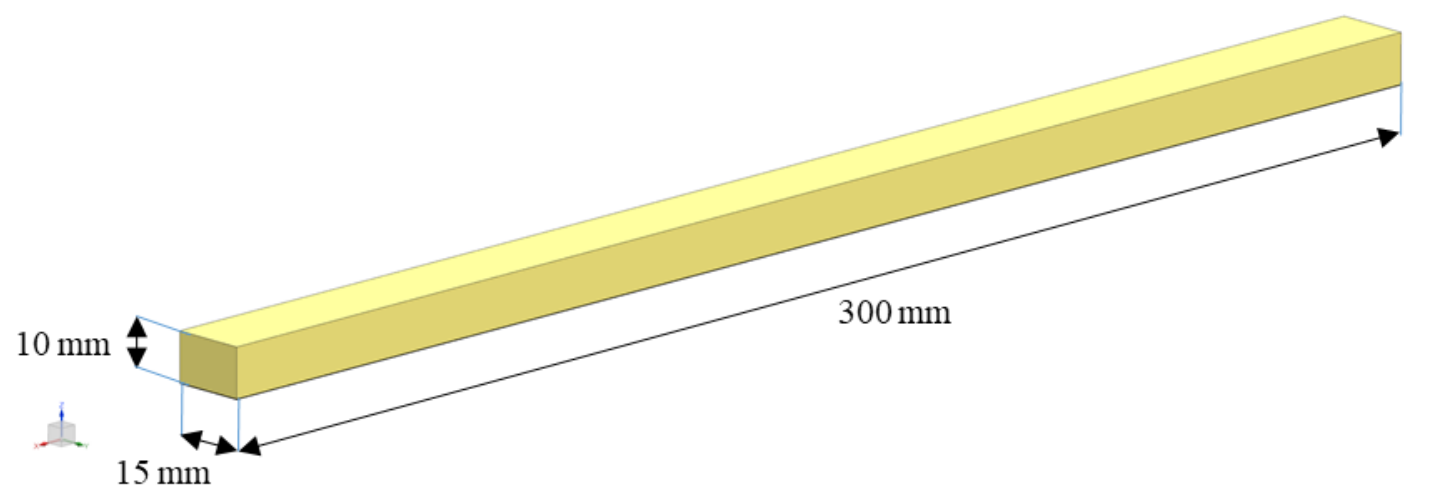

Supplementary Figure 10 Test sample

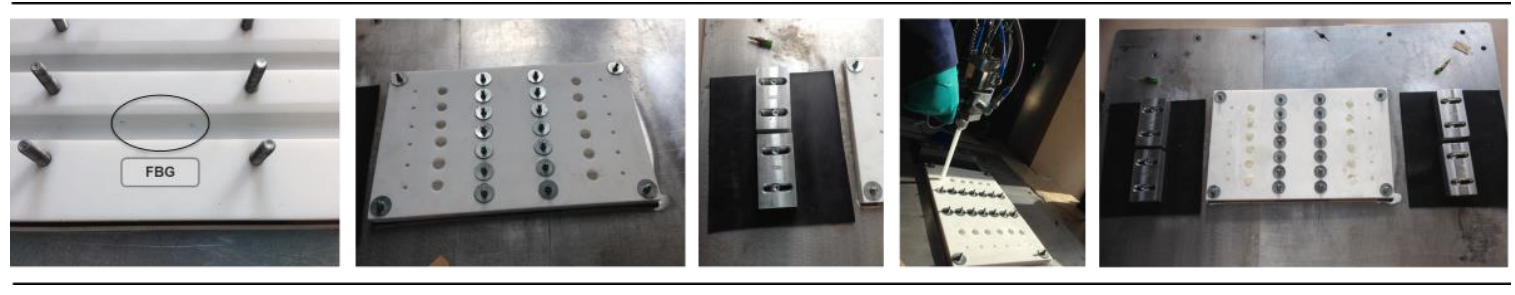

Supplementary Figure 11: Sample production process 